\title{
Literatura infantil: Una herramienta primordial para el desarrollo de los niños de preescolar
}

\author{
Children's Literature: \\ A primary tool for the integral development of preschool children
}

\author{
Andrea Arredondo QUICENO ${ }^{1}$ \\ Bárbara Cortella PEREIRA 2 \\ Rosemar Eurico COENGA ${ }^{3}$
}

\begin{abstract}
Resumen
Con el objetivo de analizar la contribución de la literatura infantil, especialmente, de tradición oral al desarrollo de la primera infancia, se realizó una investigación de maestría en educación de enfoque cualitativo, bajo una observación participante donde se desenvolvieron una serie de actividades con literatura de tradición oral en niños de preescolar en Antioquia-Colombia. Los resultados permiten constatar que el trabajo literario aporta al desarrollo del pensamiento, lenguaje y las habilidades sociales a través de la cultura y la interacción social con el medio contiguo, así pues, estos tipos de actividades pueden ser aplicables en cualquier contexto del ser humano.
\end{abstract}

Palabras claves: Literatura Infantil. Géneros de Tradición oral. Preescolar. Colombia.
Abstract

In order to analyze the contribution of children's literature and genres of oral tradition to the development of early childhood, a qualitative research was performed, through a participant observation methodology, where a series of activities with oral tradition literature in children were developed of preschool in the region of Antioquia-Colombia. The results allow to assert that activities with literature in children contributes to the development of thought, strengthening of language and social skills through culture, interaction with others and with the surrounding environment, thus, these types of activities can be applicable in any context of the human being.

Keywords: Children's literature. Oral tradition Genres. Preschool. Colombia.

1 Docente catedrática del Tecnológico de Antioquia- Institución Universitaria, Licenciada en educación preescolar (2015), Magíster en educación (2020) por la (UFMT/PPGE/Cuiabá) e integrante del Semillero de Investigación EDILEDI de la Universidad de Antioquia. Latttes: http:// lattes.cnpq.br/4777717850916421. Orcid: https://orcid.org/0000-0001-7302-8862. E-mail: andre-arredondo23@hotmail.es

2 Profesora de la Universidad Federal de Mato Grosso (UFMT/PPGE/DEOE/Cuiabá) y líder del Grupo de Estudio e Investigación "Lenguaje Oral, Lectura y Escritura en la Infancia" (GEPLOLEI). Licenciada en Pedagogía (2006), Magíster en Educación (2009) y doctora en Educación (2013) por la UNESP, campus de Marília. Realizó un intercambio en su doctorado en la École des Hautes Études en Sciences Social (EHESS), París, Francia. Lattes: http://lattes.cnpq.br/6615374490879599. Orcid: https://orcid.org/0000-0003-4068-6417. E-mail: barbaracortella@gmail.com

3 Profesor del Programa de Posgrado de la UNIC/IFMT. Licenciado en Letras (1995), Magíster en Educación (2003) y Doctor en Teoría Literaria y Literatura (2011) por la UnB. Lattes: http://lattes.cnpq.br/6784437572638138. Orcid: https://orcid.org 0000-0001-9317-8120.

E-mail: rcoenga@gmail.com 


\section{Introducción}

La experiencia literaria brinda al lector las coordenadas para que pueda nombrarse y leerse en esos dos mundos simbólicos que otros seres humanos construyeron. Aunque leer literatura no transforma el mundo, puede hacerlo al menos más habitable, pues el hecho de que nos veamos en perspectiva y miremos hacia adentro, contribuye a abrir nuevas puertas para la sensibilidad y la comprensión de nosotros mismos y de los demás (REYES, 2012, p.27-28, traducción libre $)^{4}$.

En el mundo actual, la educación y la cultura son fundamentales para la creación de espacios y de herramientas útiles para el desarrollo personal, cognitivo y social de cada individuo. Por esto, se hace necesario plantear propuestas de alto impacto para mejorar el sistema educativo y poder transformar los procesos de enseñanza- aprendizaje en la primera infancia, etapa que comprende desde la gestación hasta los cinco años de vida, considerándose como el ciclo crucial para desarrollo integral ${ }^{5}$ del ser humano. (PINO, 2005).

Dentro de las capacidades cognitivas y sociales se encuentran los procesos de oralidad, de lectura y de escritura (QUICENO, 2020; OLIVEIRA, DELMONDES, 2019), considerados como fundamentales en la infancia. Es menester señalar que en las primeras etapas de formación aún se presenta una ausencia en las metodologías aplicadas para el desarrollo de estos. El Ministerio de Educación Nacional de Colombia (MEN, 2017), estipula que no hay prisa para aprender a leer y escribir, ni hay una edad precisa para alcanzarlo, se debe crear en la infancia el deseo de interpretar y entender ese mundo simbólico que lo llevará a la consecución de ese aprendizaje, no es necesario forzar este proceso, pero es indispensable que los profesores promuevan el interés de sus alumnos a través de vivencias enfocadas al alcance de este tipo de habilidades y comprender el uso social y correcto del lenguaje. En esa perspectiva, el escenario escolar es el máximo influenciador en el proceso evolutivo del individuo el cual debe de reconocer al niño como protagonista de su aprendizaje teniendo en cuenta el medio en el cual se desenvuelven, la educación se debe basar en el disfrute de las prácticas que lo llevan a vincularse e identificarse con componentes de la cultura

4 Las citaciones en portugués fueron traducidas al español de forma libre por los autores de este artículo.

5 Entendemos la integralidad como el óptimo avance y maduración en las áreas cognitivas, psicológicas y socioculturales de cada persona. 
a la que pertenecen, contribuir al gusto por la lectura y a la construcción de competencias lingüísticas y acercarlos a la literatura a través de los libros para poder formar una infancia lectora y escritora.

La lectura, cita nuevamente Emilia Ferreiro (2002), es un derecho, no un lujo, ni una obligación. No es un lujo de las élites que se asocie con el placer y la recreación, ni es una obligación para la escuela. Es un derecho de todos, que además permite un ejercicio pleno de democracia (CASTRILLÓN, 2011, p. 190, traducción libre).

La Teoría Histórico-cultural de Vigotsky (1989), menciona que percatarse de que cada niño aprende a ser humano según lo que la naturaleza le provee en su nacimiento es una condición necesaria pero no suficiente para promover su desarrollo. Es decir, la mayoría de las habilidades para alcanzar el autoconocimiento, comprender el funcionamiento de la vida y fortalecer los procesos de pensamiento se desarrollan por medio de las interacciones sociales y la relación con el medio, lo que le permite interiorizar conceptos y fortalecer su personalidad y posteriormente conquistar funciones psicológicas como: El pensamiento, el habla, la imaginación y la memoria, funciones de la conciencia que intervienen en el desenvolvimiento de la inteligencia.

Uno de los artefactos culturales más importantes y provechosos de la humanidad es la literatura, conocida como el conjunto de producciones literarias orales o escritas caracterizadas por tener un lenguaje sencillo y expresiones fáciles de comprender para desenvolver fantasía, imaginación, creatividad y conocimiento. Sus manifestaciones son integradas a la palabra con finalidad artística, ¡La literatura es arte! y claramente les interesa a los niños. (CERRILLO Y SANCHEZ, 2001). Por ese motivo se pretende demostrar que el trabajo con la literatura no solo forma un lector desde la etapa infantil, sino que fomenta en ellos una crítica literaria y les proporciona avances en sus dimensiones del desarrollo (CALLES, 2005).

[...] La literatura debe ser leída-vale decir: sentida- a partir de la propia vida, quien escribe debe estrenar las palabras y reinventarlas cada vez, para impartir su marca personal. Quien lee recrea ese proceso de invención para descifrar y descifrarse en el lenguaje del otro. Es ese proceso complejo que implica, para decir lo mínimo, a dos sujetos con toda su experiencia, con toda su historia, con sus lecturas previas, con sus sensibilidades, con su imaginación y con su poder de situarse más allá de si mismos. Se trata de una experiencia 
de lectura compleja, y se debe decir, difícil. Más pasible de ser enseñada y para enseńarla conviene partir de su esencia (REYES, 2012, p. 26, traducción libre).

El presente artículo se centra en el análisis de la contribución del uso de la literatura de tradicional y de los diferentes tipos de géneros literarios para el desarrollo integral en la primera infancia como un eje impulsador de emociones, creador de pensamiento y de imaginación, amplificador de posibilidades de aprendizaje y fortalecedor de los procesos lingüísticos por medio del intercambio cultural con un legado que se ha venido dejando de generación en generación. Los resultados de esta investigación de maestría ${ }^{6}$ concluida y vinculada al Programa de Pos-grado en Educación de la Universidad Federal de Mato Grosso (UFMT-Cuiabá-Brasil) y al Grupo de Estudio y Investigación "Linguagem Oral, Leitura e Escrita na Infância" (GEPLOLEI), fueron obtenidos gracias a un trabajo práctico-pedagógico con niños de 5 y 6 años en el municipio de La Estrella en el departamento de Antioquia-Colombia.

\section{La literatura infantil en Colombia.}

Colombia, concibe la educación infantil como: "Un proceso continuo y permanente de interacciones y relaciones sociales de alta calidad, oportunas y relevantes, que permiten que los niños fortalezcan sus capacidades y adquieran habilidades para la vida" (MEN, 2017). Y define la Literatura como "El arte de jugar con palabras escritas y de tradición oral que hacen parte del patrimonio cultural de la familia y del contexto de los niños y niñas y la orientación pedagógica para la educación infantil”. (MEN, 2017).

$\mathrm{Al}$ articular estos dos conceptos, se evidencia que el trabajo con literatura en la primera infancia constituye al conocimiento del mundo subjetivo para el posterior dominio del medio que lo rodea y viceversa, es decir, una posibilidad de apropiarse del conocimiento que el mundo le ofrece a través de actos culturales que han existido desde hace muchos años e interiorizarlos para su propio avance en las dimensiones del desarrollo: Cognitivo, comunicativo, social y corporal. Teniendo en cuenta que todas las vivencias en estos primeros ańos junto con conocimientos alcanzados, se convierten en la base para la adquisición de las próximas etapas del desarrollo. Como una cadena donde cada paso se une con el otro y forman un todo.

6 Esta investigación se vincula al grupo de estudio GEPLOLEI "O processo discursivo no ensino inicial da leitura e da escrita para crianças" de las escuelas municipales de la ciudad de campo en Mato Grosso, se trata de un proyecto trianual (2018/2021), con perspectiva colaborativa para el planeamiento y la ejecución de las acciones con la literatura infantil entre investigadoras y profesoras iniciantes. 


\section{La tradición oral: El linaje de la literatura infantil}

La tradición oral se refiere a un conjunto de producciones literarias que funciona como un espejo, en el que una comunidad reconoce su identidad de pueblo como si fuera una proyección en el pasado y que transmite lo ancestral a través de la denominada: "Narración de historias tradicionales". (BARCIA, 2004, p.17).

En la antigüedad, la tradición oral no se considerada como un tipo de literatura, la literatura se definía sólo a la palabra escrita. Fue con el pasar del tiempo que la Real Academia de la lengua expandió esa definición extendiendo la dimensión de la literatura a lo transmitido de generación en generación (ZAPATA, 2008). En los pueblos ancestrales, esta tradición, se basa en el lenguaje oral como expresión de significado y de sentido de cultura, que sirve de vehículo para perpetuar eventos importantes que ocurrieron en la ciudad y han formado parte de su memoria colectiva. Su potencial va más allá de la palabra y tiene en cuenta la entonación, los gestos y la expresión corporal (GONZALEZ, 2012).

Es por esto que la literatura, las habilidades lingüísticas, la lengua española y extranjera son áreas fundamentales y obligatorias, las cuales deben estar dentro del Proyecto Educativo institucional (PEI) y las escuelas deben trabajar sobre una propuesta teórica a través del análisis de diferentes producciones literarias, audiovisuales, clásicas y contemporáneas (MEN, 2017).

\section{El valioso encuentro entre la literatura de tradición oral y la primera infancia}

El hombre es considerado un creador de valores culturales por medio de la interacción con el otro como un recolector de experiencias y conocimientos que posteriormente le permiten transformar su ambiente y transmitírselo a los más pequeños con el fin de crear una memoria histórica que será transmitido también para otros como necesidad de retornar a sus raíces y reencontrarse (GARCIA, 2008).

Contar y escuchar historias están entre las actividades que más estimulan nuestra imaginación. El cuento de tradición popular, siempre ha estado asociado a los estudios folclóricos en el reciente interés de estudios literarios a este rico material, considerado mucho tiempo como una condición de producción poco valiosa. La presencia de tradición oral en la constitución de género infantil y juvenil ha crecido mucho en el mercado editorial. En una publicación en 2012 de las investigadoras Vera Teixeira de Aguiar y Alice Áurea Penteado 
Martha, demostraron ese camino, organizando una colección llamada "Conto e reconto: das fontes à invenção". Además en las discusiones académicas sobre la narrativa de tradición oral, llama la atención el crecimiento del número de obras que retoman esa tradición en los días de hoy, cuyo tratamiento editorial e grafico se viene mostrando más sofisticado. La Literatura infantil, en este caso representada por los cuentos clásicos, ha ido trabajando de la mano con los diferentes géneros de tradición oral. Esta tradición literaria popular de la cual hacen parte los cuentos, los trabalenguas y las adivinanzas se dieron gracias a la influencia de varias culturas como: la cultura indígena, la cultura africana y la cultura europea que sobreviven en la actualidad y enriquecen el trabajo en el preescolar (RODRIGUEZ, 2000).

Hablar de cultura e historia nos invita a hablar de tradición oral y de sus géneros, la cultura les permite a los individuos crear sus formas de comunicación, sus expresiones y su forma de ver el mundo. El cuento clásico según Cascudo (1984) precisa ser viejo en la memoria del pueblo, divulgado en su conocimiento y persistente en el repertorio oral que se conserva en la memoria del niño para siempre de generación en generación y que satisface su vida interior. Esto ocurre porque las historias se desarrollan en el mismo plano en que el niño se encuentra respecto a sus aspectos psicológicos y emocionales. El cuento es una herramienta que permite identificar y situarse en diferentes tiempos, espacios y personajes generando una percepción del mundo para establecer sus propias ideas. Por su lado, Irwin (1960) indica que la lectura sistemática de historias para niños de más de 18 meses aumenta su vocabulario espontáneo, desarrolla la imaginación y les ayuda a apreciar la naturaleza, las personas, las experiencias y las ideas de una forma innovadora y diferente. Al leer una historia en la infancia se incrementa la valorización de cada individuo y de su pensamiento y por medio de esa experiencia entender diferentes puntos de vista.

Otro género que hace parte de la literatura de tradición oral que contribuye bastante en el trabajo en la educación infantil son los Trabalenguas, considerados como un tipo de literatura oral popular. Para Garvey (2001, p. 24) así como el juego, los trabalenguas permiten al nińo conocerse a sí mismo, conocer su entorno y sus pares, descubriendo la manifestación del lenguaje como papel social, su estructura es específica y de función lúdica utilizados para ejercitar la dicción y desafiar la pronunciación de palabras y combinaciones difíciles para la ampliación de su vocabulario. (GOMES; FERREIRA, 2003, p.20). Aunque, pronunciarlos sea difícil, es un atractivo para los nińos pues les permite entender y alcanzar el uso correcto del lenguaje. El desafío se encuentra en la capacidad de decirlos de manera rápida y correcta, con los menores errores posibles, lo que les permite aumentar la confianza en sí mismos. Cabe resaltar que algunos de los problemas de lenguaje pueden ser identificados y corregidos gracias al uso 
de este esté género. Según Murray (2004), los trabalenguas forman parte del llamado folclor de Pueblo que implementa palabras nativas, por tal motivo, es posible encontrar diferentes versiones de ellos.

Las adivinanzas por su parte, son un juego de palabras, tipo acertijo que contiene un pequeño misterio expresado en palabras (MACÍAS, 2013). Generalmente se presentan en versos cortos que contienen una pregunta y es el interlocutor quien debe descifrarlo, fortaleciendo los procesos mentales y las habilidades de pensamiento necesarios para el proceso de lectura y escritura y que al mismo tiempo enriquecen el manejo del lenguaje, según Cascudo (1998), las adivinanzas se consideran como uno de los géneros universales favoritos de todos los pueblos y en todas las épocas y no existe en la tradición oral ningún otro género que presenta mayor número de obras primas de síntesis. Para De La Serna (2001), son una manifestación viva de la literatura oral de todas las culturas, sus orígenes están íntimamente ligados a las sociedades orales que actuaban como emisoras y posteriormente fueron creadas las primeras compilaciones escritas de esa manifestación lúdica. De acuerdo con este autor, las adivinanzas son y serán tradicionales porque por medio de estas respuestas, hay situaciones desconocidas que se vuelven conocidas y resuelven circunstancias a través del pensamiento y la palabra. Otro tipo de manifestaciones de los géneros orales amados por la infancia, son los de tipo musical, generalmente conocidas como Rondas Infantiles o Canticos y que guardan una estrecha relación con el universo infantil (MARTÍN, ESCOBAR E CARBAJO MARTÍNEZ, 2009). Mencionaban que las letras de las canciones infantiles son generalmente simples para facilitar el entendimiento y la memorización y además ayudan al desarrollo del habla alrededor de los primeros ańos. En ese sentido, las canciones infantiles representan el lenguaje por medio de un ambiente musical, cantar es para ellos una necesidad que construye una acción espontánea y desenvuelve la capacidad de expresión artística y afectiva, realizar actividades de canto tiene un gran valor educacional pues trabaja con el contenido emocional que compone todo el aprendizaje. Es decir, son una forma de expresión oral que les permite comunicar sus emociones por medio de la música y se pueden interpretar de manera diferente según sea su localización y cultura. Una excelente introducción al texto seria actividades con el canto y la música. Validadas como un estímulo alegre en la perspectiva de los más pequeños (COELHO, 2000). Es menester decir que para Vigotski (1995) el juego y las actividades compartidas son un recurso sociocultural que tiene el papel de promover la evolución mental de los niños, facilitando el avance de las funciones psicológicas superiores como la atención, el lenguaje y la memoria. 


\section{La vivencia con literatura infantil con un grupo de preescolar en Antioquia}

Se utilizó para esta investigación una metodología de enfoque cualitativo, que hace referencia al contacto directo, frecuente y prolongando entre el investigador y los autores sociales dentro de sus contextos siendo el propio investigador e instrumento de la pesquisa.

De acuerdo con esa perspectiva, interactuar con los nińos durante un determinado tiempo, no en situación de test, sino conviviendo con ellas y con las profesoras a fin de "conocer y comprenderlos procesos de lectura y escritura en el juego de las interacciones sociales". (SMOLKA, 2012).

[...] Es el propio movimiento interdiscursivo, intertextual el que está marcado en las narrativas de los niños. Movimiento interdiscursivo, trabajado en el espacio de elaboración y de interacción enunciativa en la relación dialógica entre ellos. Movimiento intertextual porque incorpora lo que dice el otro, articula varias voces (SMOLKA, 1993, p. 95, traducción libre).

Con esta metodología, los niños se convierten en participantes activos y productores del discurso apropiados del lenguaje como bien cultural con capacidad de interpretar el mundo en la práctica cotidiana. También se recurrió a la observación participante con el objetivo de elaborar después de cada sección de observación, descripciones cualitativas y de tipo narrativo que permitieron obtener información relevante para esta investigación.

En las ciencias sociales, el investigador se convierte en miembro activo de un grupo o de una organización para estar inmerso en el progreso de los eventos que quiere analizar. El investigador espera que esta posición privilegiada le permita obtener más información o conocimientos más amplio de lo que sería posible si estuviera observando desde afuera (VINTEN, 1994). Es una metodología enfocada esencialmente a la atribución de significados, a las prácticas humanas encaradas sobre la perspectiva de insiders SPRADLEY, 1980). El investigador espera descubrir realidades y significados relevantes para fundamentar en términos empíricos las teorías psicosociales sobre la existencia y la práctica humana (JOGERNSON, 1989).

Las intervenciones pedagógicas con la literatura de tradición oral fueron realizadas con el fin de demostrar su importancia y aportar en la formulación de proyectos de aprendizaje para un óptimo progreso cognitivo y cultural a partir de la interacción con la cultura, con los otros y con las experiencias que el medio ofrece, 
en términos de Vigotski (1989), abrir un camino para la conexión entre biológico (natural) y lo social (cultural) en el proceso educativo de los nińos de preescolar. Este mismo autor contribuye que la enseñanza-aprendizaje es un proceso benéfico de transformación cognitiva y social que ocurre en un contexto colaborativo, aprendido a través de la observación y participación con otros individuos y la mediación de artefactos culturales a los cuales el individuo pertenece.

Teniendo en cuenta esta postura y la importancia de la relación sociocultural establecida entre el ambiente social y la educación infantil, podemos considerar la cultura como mediadora del proceso educativo y que opera teniendo en cuenta sus propias normas, creencias y significados a la hora de relacionarse con los otros y con el entorno. Se llevó a cabo un estudio de las vivencias con la literatura infantil como un estilo de narración para contar historias que educan y a su vez entretienen y contribuyen al desarrollo de diferentes competencias construcción de pensamiento crítico, desarrollo de la imaginación, y fortalecimiento del proceso lingüístico y oral.

Tales actividades pedagógicas en las que se usaron géneros de tradición oral se realizaron con un grupo de preescolar de la "Institución Educativa Concejo Municipal La Estrella" (IECME) del municipio La Estrella en Antioquia con un grupo de 21 estudiantes entre 5 y 6 años. Algunos episodios de enseñanzaaprendizaje se describen a continuación.

El primer género trabajado fue el cuento clásico llamado "La vendedora de Cerillas", de Hans Christian Andersen con el cual se fue identificando a medida de su lectura los personajes, el tiempo de la historia el contexto, así como se iba imaginando a partir del avance de la lectura lo que la historia podría contener, después de ser leída, se realizó el ejercicio de pensar otro título para este.

\section{Ilustración 1 - Dibujo "Vivir en una cajita"}

Shantal (5 años), Dibujo sobre el cuento y su nuevo título.

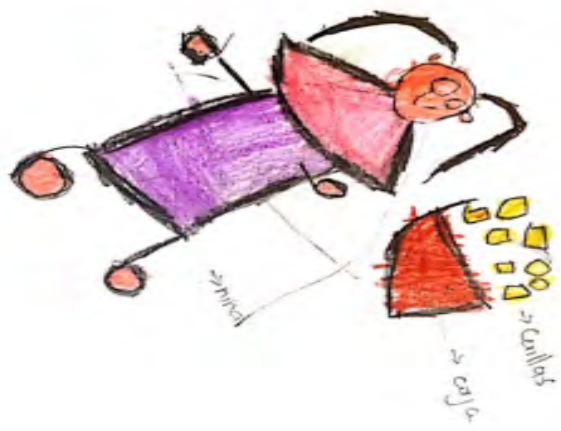

Fonte: Acervo personal de los pesquisadores 
Ilustración 2 - Dibujo"Colecionando cerillas".

Tomás (5 años), Dibujo sobre el cuento y su nuevo título.

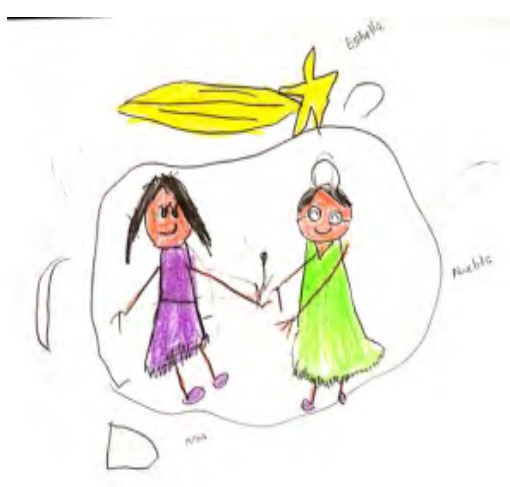

Fuente: Acervo personal de los investigadores

De acuerdo con la historia contada, ellos dibujaron la escena que más les gustó y que expuso para los demás contando el nuevo título según su percepción. Con este tipo de actividad se consigue ampliar el vocabulario, se les permite dominar sus saberes previos y estimular la imaginación y la fantasía. También esta actividad nos permitió constatar el pensamiento que presenta Ana Luiza Smolka (2010), cuando comenta la obra de Vigotski "Imaginación y crianza en la infancia” en la cual plantea que el dibujo en esta etapa de la infancia es su actividad favorita pues le ofrece al niño la posibilidad de expresar con facilidad todo aquello que domine,su creación literaria y verbal. Se comprobó así mismo el postulado de Vigotski (1995), sobre la psicología del arte, la cual propone que el dibujo representa y transmite por medio de él y de la oralidad la posibilidad de innovar en el pensamiento, en la formación del imaginario y en el aporte a la naturaleza, produciendo nuevas formas de ver la vida que a su vez permiten la internacionalización y el desenvolvimiento relacionado con la apropiación de la cultura, lo que implica una participación de ellos en su proceso de evolución e interiorización de símbolos (lenguaje) como soporte para adaptarse a su cultura.

El trabajo con trabalenguas se realizó con narraciones de este tipo:

1. Compre pocas copas, pocas copas yo compré. Como compré pocas copas, pocas copas pagaré.

2. Tres tristes tigres comen trigo en un trigal. Tanto trigo tragan que los tres tigres tragones con el trigo se atragantan.

3. El cielo está enladrillado, quien lo desenladrillará, aquel que lo desenladrille un buen des enladrillador será. 
La dinámica para este trabajo se efectuó por medio del colectivo, los niños debían de reconocer primero el contexto, de que se estaba hablando, que lugar era, y que palabras eran las más difíciles de pronunciar, luego de esto se hizo la narrativa de los trabalenguas de forma grupal, es decir todos al mismo tiempo y por último ellos elegían su turno para ir recitándolo individualmente. Al terminar este encuentro se observó que estos agentes externos cuando son incorporados al cerebro abren caminos para procesos cognitivos y la apropiación de nuevas palabras, operando en su crecimiento integral por medio da interacción verbal dentro de las aulas de clase, permitiéndoles también el disfrute de sus nuevas conquistas orales y el desafío de los alumnos al recitarlos de manera clara y rápida, cometiendo los menores errores posibles. Con esta herramienta se contribuye al fortalecimiento de su confianza y se identifican problemas de lenguaje.

La vivencia con los trabalenguas enriqueció el campo social a medida que iba propiciando una experiencia diferente por medio de la interacción con los otros en las actividades sociales compartidas. Además de que es muy significativa porque hacen parte del llamado folclor del Pueblo por la implementación de palabras nativas, si bien tienden a dificultar su pronunciación, los invita a entender y conseguir el correcto uso de su lengua. (MURRAY, 2004).

El abordaje con las adivinanzas se hizo a partir de un conversatorio en el cual se iban lanzado de forma oral las pistas para descifrar este acertijo, a medida que ellos hacían su proceso de información, pensaban e iban dando la respuesta que consideraban y así hasta acertar y adivinar de forma correcta la adivinanza. Los acertijos utilizados fueron:

1. Tiene ojos y no ve, posee corona y no es rey, tiene escamas sin ser pez, que cosa rara es: "La Piña".

2. Verde por fuera, roja por dentro y tiene bailarinas en el centro: "La Sandia"

3. Me llamo Leo, me apellido Pardo, quien no me adivine es un poco tardo. "El Leopardo".

4. Llevo mi casita a cuestas, camino con una pata y voy dejando mi huella con un hilito de plata: "El Caracol".

5. El roer es mi trabajo, el queso mi aperitivo y el gato siempre ha sido mi terrible enemigo: "El Ratón"

6. Soy una hermosa señora con cresta, plumas y pico y he puesto un balón pequeño que te puedes comer frito. "La Gallina".

7. Blanca por dentro, verde por fuera, si quieres que te lo diga espera: "La Pera". 
Otro género analizado y planeado en varios encuentros, fue el de canciones infantiles, conocidas también como rondas. Para familiarizarlos con este tipo de música, es importante saber qué tipo de rondas disfrutan más y comenzar a trabajarlas en un espacio no solo de ocio, sino de aprendizaje. Otra idea muy llamativa y representativa para ellos es la creación de instrumentos musicales.

La forma de trabajar este género fue siempre en ronda, para presentar la canción, indagando sus saberes previos sobre estas, identificar si ya tenían conocimiento de ellas, construir lenguaje a partir de las palabras desconocidas y de los conceptos familiares, en el encuentro con ellos se acompañó con su respectivo video para un óptimo aprovechamiento de los recursos del aula como la TV con la finalidad de acompañar con movimientos y que aumentó en ellos el interés visual y la motivación.

Comenzamos el encuentro con un conversatorio que se resume a continuación: "-Qué es un instrumento musical?” - Algo para tocar. (Salomé, 5 años). “- Sabes tocar alguno?”. Si, Guitarra, maracas y piano”. Después con botellas de plástico reutilizadas y diseñadas desde casa (por motivo de tiempo en el aula), con lentejas y arenas, se creó el instrumento musical y cantamos las canciones que ya habíamos abordado en los encuentros anteriores. Esta actividad se disfrutó demasiado, ellos fueron los absolutos protagonistas de la creación del instrumento en su casa (dicho por ellos), del diseño y del resultado de este, lo que nos permitió también, conocer como es el proceso y el acompañamiento en casa, como sus padres o cuidadores están involucrados en el fortalecimiento de los procesos escolares, como hemos dicho, el medio es indispensable en la conquista de todas las áreas del desarrollo en la etapa infantil. Al ser creada desde la casa hizo que la actividad fuera más exitosa, porque ellos llegaban motivados desde casa, curiosos por lo que iba a suceder y de eso se trata, de crear espacios que contribuyan a la motivación por el espacio escolar, no como algo impuesto por el contrario como una experiencia llena de alegría y concentración. Conforme pasaban las actividades ellos más se interesaban por otros encuentros y animaban a otros si se sentían desmotivados. Otra forma de hacerlo, es partiendo la actividad en 2 encuentros, uno para la creación del instrumento y para observar ese proceso motriz fino y el otro para cantar y tocar, sin embargo las dos formas de aplicarla son útiles y válidas.

Después de analizar el resultado maravilloso de esta actividad grupal se puede decir que por medio de las canciones se trabaja la representación del lenguaje a través del ambiente musical que constituye su capacidad de expresión artística como una forma de hacer arte agregado al valor educacional. Las rondas compartidas fueron: "Juan paco pedro de la mar", "El baile de los animales y Soy una serpiente". Esta práctica permitió: Atribuir significados a los eventos y 
objetos, respeto de las diferencias, organización del pensamiento, uso del lenguaje cantado y el fortalecimiento de las funciones psicológicas: Comunicación, atención, capacidad de escucha y comprensión de nuevos conocimientos.

Cantar es la forma de iniciar la vida literaria entre voces e historias, permitirles organizar la experiencia por medio de su sentir aumentando en la primera infancia las oportunidades de aprendizaje, de expresión de desarrollo, a sorprenderse de las posibilidades de movimiento que ofrece su cuerpo, a apropiarse y enriquecer el lenguaje. La base bien fundamentada del lenguaje, influye en la facilidad de manejar signos y símbolos. La intervención con este tipo de propuestas, fáciles y sencillas pero significativas como cantar y jugar con la tradición, es incorporar la vida y la cotidianidad próxima a la literatura, es una forma eficaz de garantizar el desarrollo integral en igualdad de condiciones. Conforme pasó el tiempo se evidenció un proceso de desarrollo integral, por un lado los niños mostraban mejoría de dicción y pronunciación, resolvían preguntas cada vez más complejas, sus tiempos de concentración iba aumentando de actividad en actividad y por otro lado se fortaleció el proceso de interacción social, respetar las opiniones de los demás, conocer diferentes puntos de vista, esperar el turno y cumplir reglas básicas de convivencia.

Fotografía 1- Construcción del instrumento por los niños

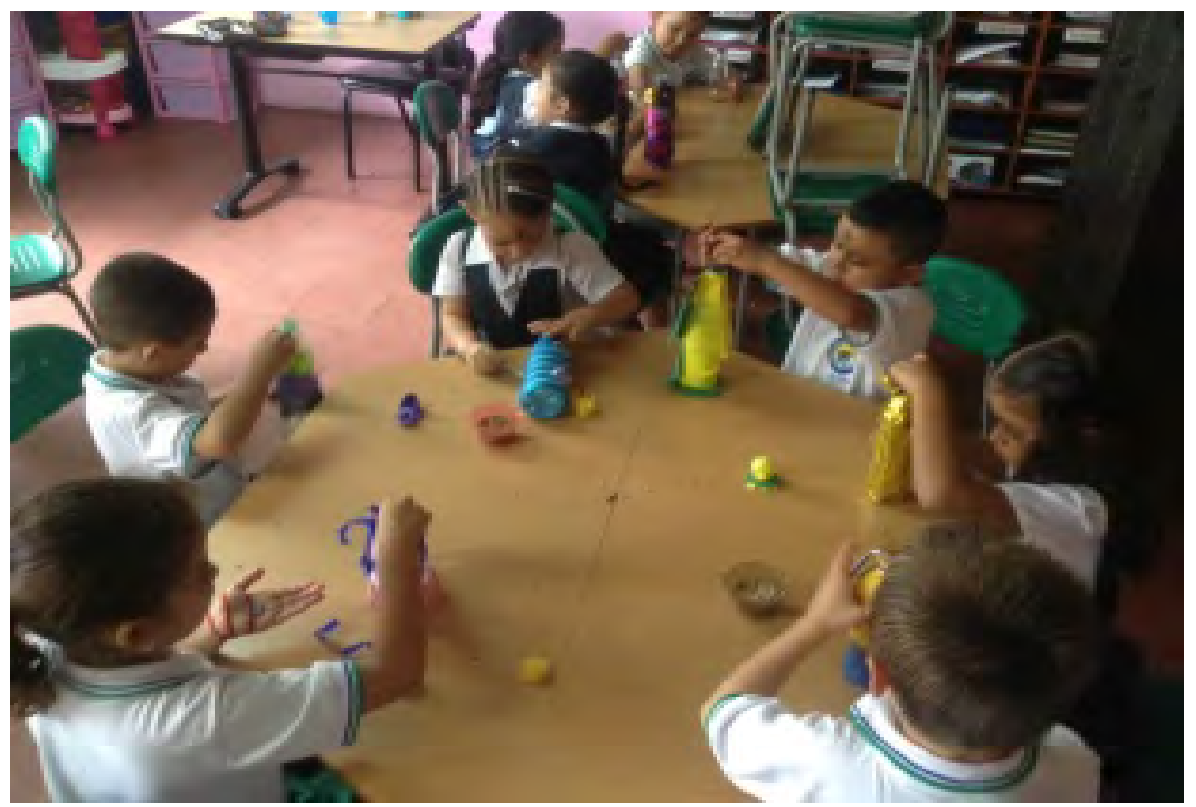

Fuente: Archivo particular de los investigadores.

Fotógrafa: Andrea Arredondo. 


\section{Consideraciones Finales}

La literatura infantil y los géneros de tradición oral utilizados: cuentos clásicos, las adivinanzas, los trabalenguas y las rondas, permiten el desarrollo integral en la primera infancia, por un lado la optimización de las funciones psicológicas superiores como el lenguaje, la memoria, la atención y el pensamiento y por otro lado benefician el desarrollo social permitiéndoles apropiarse del mundo y de la cultura a la cual pertenecen. En otras palabras, el trabajo con la literatura es un instrumento que vincula la diversión con el desarrollo de competencias lingüísticas, cognitivas y sociales y principalmente humanas, como señala Yolanda Reyes en el epígrafe de apertura del presente artículo.

Debido a esto es importante promover vivencias en la educación infantil y espacios donde se incluyan los diferentes géneros literarios para el fortalecimiento de la identidad de un pueblo y de los propios niños, la valorización del patrimonio cultural local, así como introducirlos en la cultura de la lengua escrita mediante procesos lúdicos los cuales permiten fortalecer el proceso de enseñanza y promover el interés por literatura a través del contacto directo con ella abriendo un espacio a la construcción de conocimientos y significados del mundo formando una infancia lectora y escritora protagonista de sus propias historias.

Teniendo en cuenta lo anterior, es importante resaltar que los profesores son los guías más representativos, se convierten en informantes culturales, en mediadores que construyen con sus alumnos un espacio dentro y fuera de clase ofreciéndoles diferentes oportunidades y materiales para la apropiación y comprensión del uso de sus funciones psicológicas y al mismo tiempo se convierta en productora de cultura orientando esa escolaridad a metas y objetivos para el logro del aprendizaje libre y guiado dentro del proceso formativo y proponer estrategias basadas en la interacción con el medio cultural al que pertenece descubriendo sus propias habilidades y las de sus pares por medio del intercambio de conocimientos dados per el dialogo espontáneo y cotidiano.

Sabiendo entonces que la apropiación del lenguaje es mediado por el uso de artefactos culturales como es la literatura, se necesita el uso de esta herramienta para que los nińos sean capaces de resolver problemas dentro de este, desenvolviendo al mismo tiempo todas sus capacidades cognitivas y humanas. Es importante recordar que las actividades con literatura de tradición oral brindan experiencias no solamente cognitivas sino también de alegría, factor fundamental en el proceso de enseńanza - aprendizaje que contribuirá en gran medida al avance y la mejora del sistema educativo ya que el uso de los diferentes géneros literarios generan más interés en los niños en descubrir y proponer nuevos mundos a partir de la lengua oral y escrita. 


\section{Referencias}

BARCIA MENDO, Enrique, La tradición oral en Extremadura. Utilización didáctica de los materiales. Consejería de Educación Ciencia y Tecnología de la Junta de Extremadura. Mérida. (2004).

CALLES, Josefina. La literatura infantil desarrolla la función imaginativa del lenguaje. Laurus, 11 (20), 144-155. (2005).

CASCUDO, L. C. Literatura oral no Brasil. Rio de Janeiro: José Olympio, (1984).

CASTRILlLÓN, Silvia. O direito de ler e escrever. Trad. Marcos Bagno. São Paulo: Pulo do Gato, 2011.

CERILLO, Pedro e SÁNCHEZ, Cesar. Lo literario y lo infantil: concepto y caracterización de la literatura infantil. Cuenca: Ediciones de la Universidad de Castilla- La Mancha. (2001)

COELHO, Nelly Novaes. Literatura infantil: teoria, análise, didática. - 1. Ed, São Paulo: Moderna, (2000).

DE LA SERNA, Marcos. El libro de las adivinanzas y acertijos. Editorial Victor, España. (2001).

ESCOBAR Martin e MARTINEZ Carbajo. Cancionero infantil de la región de murcia.

Escritores.org. (2001). Biografias. Escritores.org. Recuperado de: https://www. escritores.org/biografias/11674-da-coll-ivar

Garvey, C. (2001). El Juego Infantil. Madrid: Ediciones Morata S.A.

GARCÍA, B.M., (2008). El aprendizaje de la cultura y la cultura de aprender. Revista de Ciencias Sociales 21.

GOMES, Lenice. FERREIRA, Hugo. Pelas ruas da oralidade. Paulinas. Rio do Janeiro, Brasil. (2003).

GONZÁLEZ, Jenny. La oralidad: tradición ancestral para preservación de la memoria colectiva. Ars historica (4). (2012).

IRWIN, O. Infant speech: Effect of systematic reading stories. Journal of speech and hearing research 3, 187: 190. (1960).

JORGENSON, D.L. Participant Observation: A methodology for human studies. Newbury Park, CA: Sage Publications. (1989). 
MACÍAS, Elva. (2013). Tiempo de adivinar. Tuxtla Gutiérrez: Pinacoteca Editores. MINISTERIO DE EDUCACION NACIONAL, MEN. Bases curriculares para la educación inicial y preescolar. Bogotá, Colombia. Ministerio de educación nacional. (2017).

MINISTERIO DE EDUCACION NACIONAL. (2014). La literatura en la educación inicial. DOCUMENTO NO. 23 serie de orientaciones pedagógicas para la educación inicial en el marco de la atención integral. Recuperado de: http://www.deceroasiempre.gov.co/Prensa/CDocumentacionDocs/DocumentoN23-literatura-educacion-inicial.pdf.

OLIVEIRA, Barbára Cortella Pereira; DELMONDES, Cristiane Dias Santos. A Proposta Pioneira da Alfabetização como Processo Discursivo no Brasil e sua Apropriação pelas Alfabetizadoras, em Mato Grosso. Revista Brasileira De Alfabetizaçáo, v. 1, p. 126-148, 2019. Disponível em: https://revistaabalf.com. br/index.html/index.php/rabalf/article/view/337; Acesso em: 10 fev. 2021.

PINO, Angel. As marcas do humano ás origens da constituiçáo cultural da criança na perspectiva de Lev. S. Vigotsky. São Paulo, Brasil. Cortes Editora. (2005).

QUICENO, Johanna Andrea Arredondo. Práticas de oralidade e escrita em crianças de 5 anos em uma escola pública em Antioquia - Colômbia: a vivência com gêneros literários de tradição oral. 2020. 117f. Dissertação (mestrado em educação) - Universidade Federal de Mato Grosso, 2020.

REYES, Yolanda. Ler e brincar, tercer e cantar: literatura, escrita e educaçáo. Trad. Rodrigo Petronio. São Paulo: Pulo do Gato, 2012.

RODRIGUEZ Antonio. (2000). Hacia una historia de la literatural infantil en Colombia. Boletin cultural y bibliográfico. Vol. 37. num. 55. pg 142.

SMOLKA, Ana Luiza B.; Ana Luiza Smolka comenta Lev S. Vigotski: Imaginaçáo e criação na infância. São Paulo, Brasil. Editora Ática. (2012).

SPRADLEY, J. P. Participant observation. New York: Holt, Rinehart \& Winston, INC. (1980). univ.de murcia, murcia, España. ISBN 10: 8483718537. (2009).

VINTEN, G. Participant observation: A model for organizational investigation? Journal of Managerial Psychology. Bradford, 9 (2), 30. (1994).

VIGOTSKI, Lev. Pensamiento y lenguaje: Teoría del desarrollo cultural de las funciones psíquicas. Buenos Aires, Argentina. Ediciones Fausto. (1995).

VIGOTSKY, L.S. Pensamento e Linguagem. São Paulo: Martins Fontes, 1989. 


\title{
Anexo A - Autorización para la publicación de fotografías
}

\author{
UNIVERSIDADE FEDERAL DE MATO GROSSO \\ INSTITUTO DE EDUCACAOO \\ PRO-REITORIA DE ENSINO DE PÓS-GRADUAÇÃO \\ COMITÊ DE ÉTICA EM PESQUISA
}

\section{CONSENTIMENTO LIVRE E ESCLARECIDO}

Convidamos V. $\mathrm{S}^{\natural}$, pais/responsiveis pelas crianças da turma de pré-escola (Educaçälo Infantil) de uma instituiç̧̆o pública do municipio La Estrella na Antioquia - Colömbia para conceder a autorizaçăo de fotografar/filmar as vivências das crianças dessa turma e participarem como voluntírios da pesquisa colaborativa que esta sendo proposta pela mestranda Johanna Andrea Arredondo Quiceno, no curso de Mestrado em Educaçä/UFMT. MT. Após a leitura deste documento, caso aceite fazer parte desse estudo, favor assinar ao final, as duas vias, uma que ficará com os Senhores (as) e a outra para a pesquisadora responsivel. Em caso de recusa nalo haverá penalidades. As dávidas poderâo ser esclarecidas no Comitê de Ética em Pesquisa/ Humanidades da UFMT sob a coordenaç̄o da Profa. Dra. Rosangela Kätia Sanchez Mazzorana Ribeiro, pelo telefone: (65) 3615 -8935 ou pelo e-mail: cephumanas@ufmt.br.

\section{INFORMAÇOES SOBRE A PESQUISA}

Título do projeto: "Práticas de oralidade c escrita em uma turma de Pré-escola em uma escola publica de Antioquia-Colômbia"

\section{Pesquisadora responsivel}

Johanna Andrea Arredondo Quiceno

Endereco: Rua 09 *445, Boa Esperança

Telefone: (65) 999-088451

E-mail: andre-arredondo23@hotmail.es

\section{Orientadora responsivel}

Profa. Dra. Bárbara Cortella Pereira de Oliveira

Endereço: Avenida Fernando Correa da Costa, 2367, Boa Esperança

Cuiabí - MT, CEP:78.060-900

Telefone: (65) 99658-5962 e-mail: barbaracortella@gmail.com

Área de conhecimento: Ciências Humanas

Área de atuaçăo da pesquisadora: Educaçăo

\section{Deseriçào da pesquisa:}

A pesçuisa propote analizar el proceso discursivo de la ensetanza y el aprendizaje del lenguaje oral y escrito en un grupo de preescolar de una Institución pública en Antioquia- Colombia". Para alcançarmos os objetivos propostos nesta pesquisa colaborativa de caráter qualitativa, utilizaremos como téenicas: a) observaçঠ̌es da prática do cotidiano escolar; b) ofieinas colaborativas mediante o uso da literatura de tradiçăo oral, tais como as parlendas, brincadeiras cantadas (cantigas de roda, cantigas tradicionais) e trava-linguas, para crianças de 5 anos ; c) "Díario de Campo" como instrumento de registros de pesquisa. Como resultado, espera-se que o desenvolvimento dessa pesquisa contribua para of fortalecimento do debate 


\section{UNIVERSIDADE FEDERAL DE MATO GROSSO INSTITUTO DE EDUCACÁO PRÓ-REITORIA DE ENSINO DE PÓS-GRADUACȦO COMITE DE ETICA EM PESQUISA}

acerca do processo discursivo do ensino da leitura e da escrita na América Latina, particularmente, em Antioquia-Colômbia.

\section{Esclarecimentos}

Será garantido no decorrer do processo de pesquisa o acesso aos dados coletados aos responsáveis pelos participantes nela envolvidos. Essa garantia se estende a possíveis esclarecimentos e assistência que se faça necessária posteriores ao encerramento da pesquisa. Os participantes poderăo se desligar do projeto a qualquer momento do seu andamento, podendo os responsáveis retirar seu consentimento em qualquer fase da pesquisa. A identificaçăo do responsável não será exposta durante o projeto nem nas publicações do trabalho, garantindo assim 0 anonimato dos participantes, podendo os responsáveis pelos particpantes da pesquisa decidir se e quais informaçס̄es (identidades, imagem) dos participantes podem ser tratadas de forma pública. Quaisquer recursos ou reclamaç̄es poderão ser encaminhados a pesquisadora responsável. Caso ainda restem dúvidas pode ser procurado o Comitê de Ética em Pesquisa "criado para defender os interesses dos participantes da pesquisa em sua integridade e dignidade e para contribuir no desenvolvimento da pesquisa dentro de padröes éticos".

\section{Beneficios, possiveis desconfortos ou riscos decorrentes da participação na pesquisa}

Os beneficios da pesquisa săo indiretos, pois os resultados serão de caráter público, dessa forma a comunidade escolar e sociedade em geral poderăo ter acesso a pesquisa, debatêla e refletir individual e coletivamente sobre a importancia dos estudos acerca do cotidiano escolar e sobre a importância de se ouvir as crianças na pesquisa.

A pesquisa năo causará danos fisicos, psicológicos, morais, intelectuais, sociais e culturais aos particpantes envolvidos. 2019.

A referida pesquisa tem previsto em seu cronograma o periodo de fevereiro a março de

Estando assim de acordo, assinam o presente Consentimento as partes envolvidas.

Antioquia, Colômbia, 08 fevereiro de 2019.

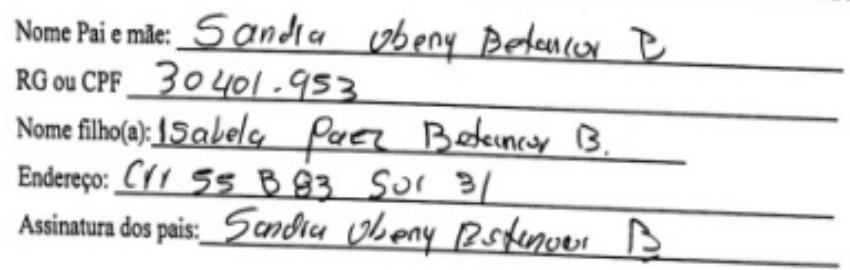

Responsivel pela Pesquisa

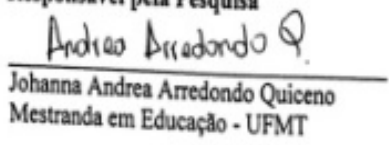

